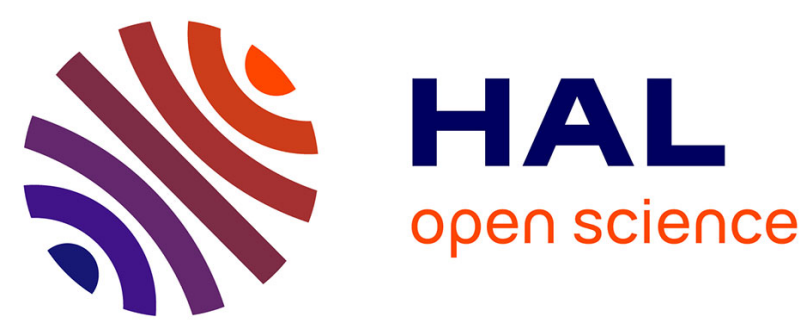

\title{
Imaging Heterogeneous Electrocatalyst Stability and Decoupling Degradation Mechanisms in Operating Hydrogen Fuel Cells
}

Isaac Martens, Antonis Vamvakeros, Nicolas Martinez, Raphaël Chattot, Janne Pusa, Maria Valeria Blanco, Elizabeth A Fisher, Tristan Asset, Sylvie Escribano, Fabrice Micoud, et al.

\section{To cite this version:}

Isaac Martens, Antonis Vamvakeros, Nicolas Martinez, Raphaël Chattot, Janne Pusa, et al.. Imaging Heterogeneous Electrocatalyst Stability and Decoupling Degradation Mechanisms in Operating Hydrogen Fuel Cells. ACS Energy Letters, 2021, pp.2742-2749. 10.1021/acsenergylett.1c00718 . hal03290343

\section{HAL Id: hal-03290343 \\ https://hal.science/hal-03290343}

Submitted on 19 Jul 2021

HAL is a multi-disciplinary open access archive for the deposit and dissemination of scientific research documents, whether they are published or not. The documents may come from teaching and research institutions in France or abroad, or from public or private research centers.
L'archive ouverte pluridisciplinaire HAL, est destinée au dépôt et à la diffusion de documents scientifiques de niveau recherche, publiés ou non, émanant des établissements d'enseignement et de recherche français ou étrangers, des laboratoires publics ou privés. 


\title{
Imaging heterogeneous electrocatalyst stability and
}

\section{decoupling degradation mechanisms in operating}

\section{hydrogen fuel cells}

\author{
Isaac Martens, ${ }^{+\neq}$Antonis Vamvakeros, ${ }^{+,{ }^{\wedge} \wedge}$ Nicolas Martinez, ${ }^{\|}$Raphaël Chattot, ${ }^{\dagger}$ Janne Pusa, ${ }^{\dagger}$ \\ Maria Valeria Blanco, ${ }^{\dagger}$ Elizabeth A. Fisher, ${ }^{\ddagger}$ Tristan Asset, ${ }^{\nabla}$ Sylvie Escribano, $\|$ Fabrice \\ Micoud, $\|$ Tim Starr, ${ }^{\circ}$ Alan Coelho, ${ }^{h}$ Veijo Honkimäki, ${ }^{\dagger}$ Dan Bizzotto, ${ }^{\ddagger}$ David P. Wilkinson, ${ }^{i}$ \\ Simon D.M. Jacques, ^ Frédéric Maillard, ${ }^{\nabla}$ Laetitia Dubau, ${ }^{\nabla}$ Sandrine Lyonnard, ${ }^{*} \|$ Arnaud \\ Morin, ${ }^{* j}$ Jakub Drnec ${ }^{*}+$
}

†European Synchrotron Radiation Facility, Grenoble, France.

¥Advanced Materials and Process Engineering Laboratory, Department of Chemistry, University of British Columbia, Vancouver, Canada.

§Department of Chemistry, University College London, London, UK.

${ }^{\wedge}$ Finden Ltd., Oxfordshire, UK.

\|Univ. Grenoble Alpes, CEA, CNRS, IRIG, SyMMES, F-38054 Grenoble, France.

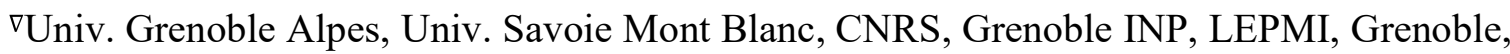
France. 
OIndependent researcher, St. Johann im Tirol, Austria.

${ }^{\mathrm{h}}$ Coelho Software, Brisbane, Australia.

iDepartment of Chemical and Biological Engineering, University of British Columbia, Vancouver, Canada.

jUniversité Grenoble Alpes, CEA, 17 Avenue des Martyrs, F-38000 Grenoble.

\title{
Corresponding Author
}

*drnec@esrf.fr, sandrine.lyonnard@cea.fr, arnaud.morin@cea.fr

\begin{abstract}
Proliferation of hydrogen fuel cell systems is hindered by degradation of the platinum catalyst. Here, we provide a device level assessment of the catalyst degradation phenomena and its coupling to nanoscale hydration gradients, using advanced operando X-ray scattering tomography tailored for device-scale imaging. Gradients formed inside the fuel cell produce heterogeneous degradation of the catalyst nanostructure, which can be linked to the flow field design and water distribution in the cell. Striking differences in catalyst degradation are observed between operating fuel cell devices and the liquid cell routinely used for catalyst stability studies, highlighting the crucial impact of the complex operating environment on the catalyst degradation phenomena. This degradation knowledge gap accentuates the necessity of multimodal, in situ characterization of real devices when assessing the performance and durability of electrocatalysts, and more generally, electrochemically active phases used in energy conversion and storage technologies.
\end{abstract}




\section{TOC GRAPHIC}

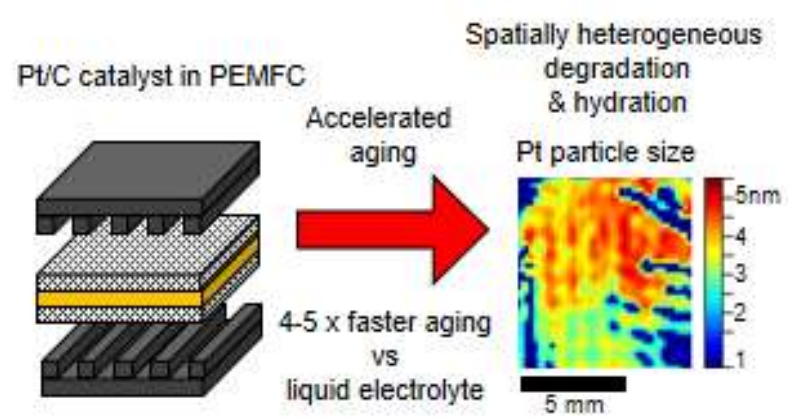

Large scale adoption of hydrogen energy systems requires reliable, cost competitive water electrolyzers and fuel cells, of which the polymer electrolyte membrane (PEM) variants are most popular. ${ }^{1}$ The performance and cost are both driven by design of a multi-layered nanocomposite membrane electrode assembly (MEA). ${ }^{2}$ Despite great progress in optimizing individual components of the PEM fuel cell (PEMFC) MEAs in laboratory model systems ${ }^{3,4}$, these advances have not always translated into improved performance at the device level ${ }^{5-7}$, because strong interactions between different components and the complex chemical environment of an operating cell hinders the integration of each component into an optimized MEA architecture ${ }^{6,8}$. These effects apply not only to catalyst activity, where poisoning of the Pt surface by ionomer is increasingly recognized as a limiting factor, ${ }^{7}$ but also to water/thermal transport, electrolyte stability, and myriad other issues related to integrated systems engineering. ${ }^{9}$ Improving the durability of high performance catalysts presents a great challenge and is limited by our understanding of the degradation phenomena. ${ }^{10,11}$ Carefully balancing the performance, durability, and cost of the oxygen reduction reaction (ORR) catalyst is necessary for technological

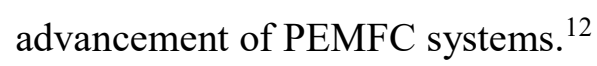


The degradation processes of Pt-based ORR catalysts have been rigorously investigated under idealized laboratory conditions (i.e. in inert atmosphere, room temperature, and ultrahigh purity liquid electrolyte). The oxidation and reduction of the Pt surface plays a central role ${ }^{13}$ with potential cycles triggering nanoparticle reconstruction and dissolution ${ }^{14}$. This leads to corrosion, Ostwald ripening and coalescence of the nanoparticles during operation, lowering the surface area and mass activity of the catalyst. ${ }^{15}$ The extent to which catalyst activity and durability measurements under idealized conditions transfer directly to the hot, gas phase polymer electrolyte MEA environment, remains an open question ${ }^{16}$, and the answer will guide development of active materials and operating protocols towards more robust performance. While much is known about degradation occurring specifically inside $\mathrm{MEAs}^{6,8,9,12,15,17-22}$, direct cell performance prediction based on rotating disc electrode studies remains challenging, especially for nanostructured catalysts, due to the phenomena discussed above.

Techniques which can simultaneously probe all the components of functional devices at the nanoscale are urgently required to optimize the MEA architecture and operating conditions. Spectromicroscopy approaches using electron ${ }^{23}$, neutron ${ }^{24}$, and photon beams ${ }^{14,21,25}$ are powerful, but generally laborious and/or limited to ex situ experiments. Significant advances in spatial and time resolution with in situ X-ray absorption tomography have been recently achieved. ${ }^{26,27}$ However, spatial resolution is often limited to scales greater than $100 \mathrm{~nm}$ and lacks the critical nanoscale and chemical information about the catalyst and supporting materials. This information is necessary to connect the catalyst activity, morphology and stability to the overall MEA performance. ${ }^{28}$ These properties determine the device's life cycle, with major impact on its economic feasibility. ${ }^{22}$ 
Here, we study the catalyst degradation phenomena in an operating PEMFC using novel high energy X-ray scattering techniques, simultaneously mapping chemical composition with X-ray diffraction computed tomography (XRD-CT) and nanostructure by small angle X-ray scattering computed tomography (SAXS-CT) across the device scale of several centimeters (Fig. 1A). ${ }^{29-31}$ XRD-CT has been previously used to investigate solid oxide fuel cells ${ }^{32}$, catalytic reactors ${ }^{33}$ and batteries $^{34}$ from hundreds of micrometers up to millimeters in size and provides atomic scale information about the used materials. To understand the degradation phenomena at the device level, we have extended these techniques to samples 10x larger than previously possible, such that entire X-ray transparent $5 \mathrm{~cm}^{2} \mathrm{PEMFCs}^{35}$ can be imaged (Fig. 1A). The voxel size (200 $\mu \mathrm{m} \times 200$ $\mu \mathrm{m} \times 50 \mu \mathrm{m}$ ) shown here is currently limited by the beam size and measurement speed, and can be optimized for larger devices down to sub-micrometer resolution using 4th generation X-ray sources. Detailed descriptions of the method are available as supplementary information.

Major advancements in computed tomography algorithms allow a direct observation of the rapid heterogeneous nanostructural deterioration of the MEA. Catalyst aging was explored under two different degradation conditions: under a potentiostatic hold at $1 \mathrm{~V}$, and through a commonly used cyclic voltammetry accelerated stress test (AST). The catalyst degradation is directly linked to the formation of chemical and/or temperature gradients, correlated to the water distribution in the cell materials, and imprinted by the macroscale geometry of the flow field. Evidence of heterogeneous aging has been previously observed in end-of-life samples using ex situ analysis with $\mathrm{TEM}^{18}$ or X-ray diffraction ${ }^{20}$. Characterizing and predicting the gradients at different operating conditions and integrating the structural evolution of electrocatalysts with fuel cell design will be increasingly necessary to mitigate degradation and lower the cost of the technology.

\section{D chemical mapping using X-ray scattering tomography}




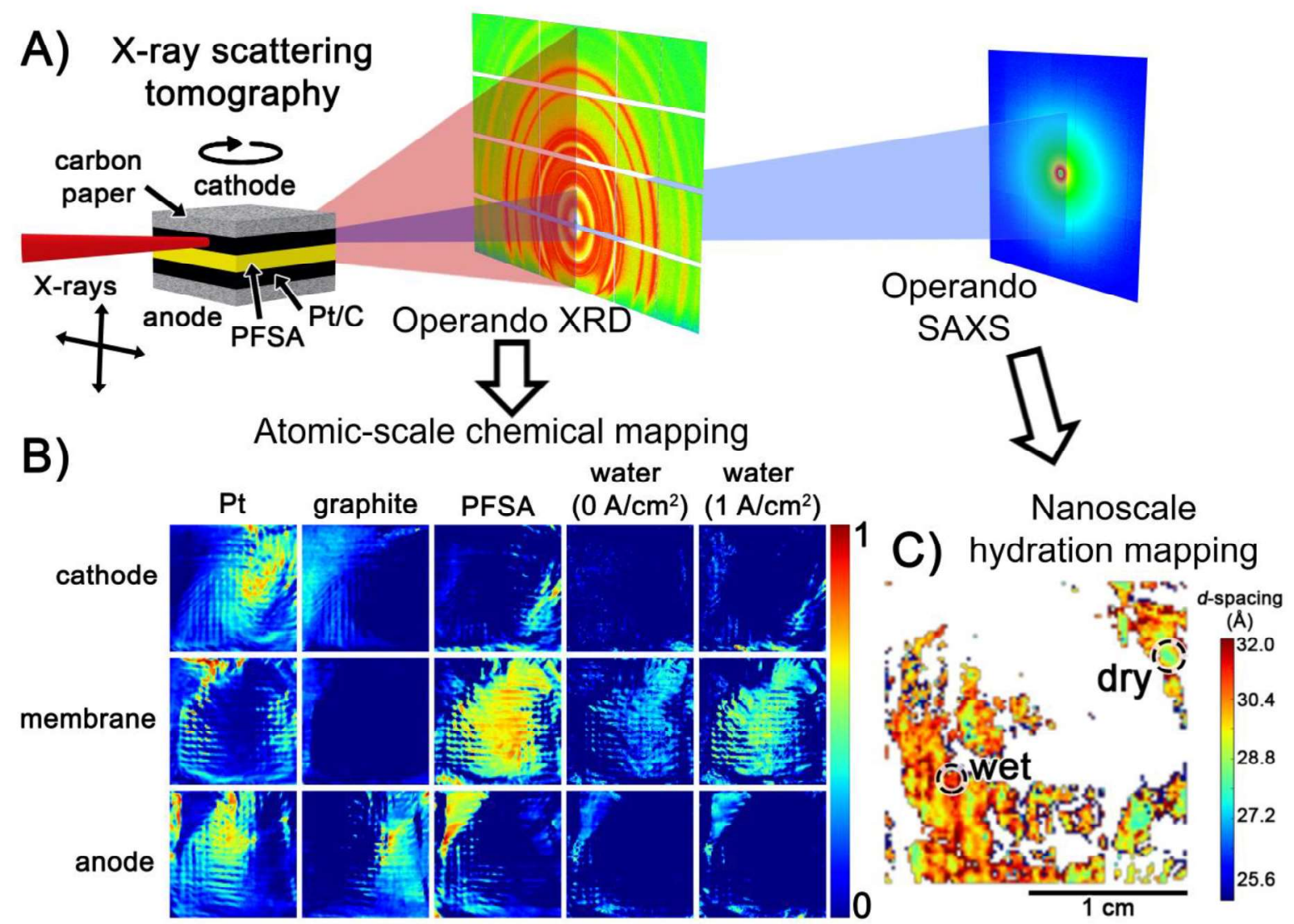

Figure 1. In situ X-ray scattering tomography of a fuel cell membrane electrode assembly. A) Schematic of the grazing incidence diffraction tomography. B) Chemical maps of tomography slices collected through the cathode, PFSA membrane, and anode and obtained by simple deconvolution of reconstructed XRD patterns. Each map in B) is $1.9 \mathrm{~cm}$ across, $200 \mu \mathrm{m}$ resolution, measured over the central region covered by the flow field of the $5 \mathrm{~cm}^{2}$ cell. The cell was operated at $80^{\circ} \mathrm{C}$ and $100 \%$ relative humidity. The three slices were collected at $1 \mathrm{~V}$, and during operation at $0.6 \mathrm{~V}, 1 \mathrm{~A} / \mathrm{cm}^{2}$. C) SAXS tomography of slice through the PFSA membrane in a separate experiment, collected at $0.8 \mathrm{~A} / \mathrm{cm}^{2}, 75^{\circ} \mathrm{C}, 80 \%$ relative humidity. The color indicates the $\mathrm{d}$-spacing of the ionomer phase segregation, reflecting local hydration. 
The main advantage of XRD-CT is its superior chemical contrast in comparison to standard absorption-contrast tomography (Fig. 1B). The chemical maps, which can be merged into 3D images (Fig. S1), reflect the intrinsic heterogeneous nature of the PEMFC largely imprinted by the flow field design. The color mapping is normalized for each phase to the highest intensity detected across all three slices. Compression of the flow field induces wrinkling in the MEA, on the order of a few microns, generating lined patterns in the Pt and ionomer signals (note that the parallel channels of the cathode and anode plates were aligned perpendicular to each other). ${ }^{19}$ This heterogeneous pressure field alters mass and thermal transport, as well as the mechanical properties of the electrodes, generating chemical gradients $\left(\mathrm{H}_{2} \mathrm{O}, \mathrm{O}_{2}, \mathrm{pH}, \mathrm{Pt}^{2 / 4+}\right)$ inside the cell and defining the nanoscopic degradation phenomena in the catalyst layer, which we will show later. One of the most important aspects of fuel cell operation affected by the flow field is the water transport and distribution inside the catalyst layer, gas diffusion layer, and ionomer membrane, which is critical for obtaining maximum cell performance. ${ }^{26,36}$ XRD-CT allows the spatial distribution of liquid water to be obtained from the amorphous background of the XRD patterns (Fig. 1B, detail in S5). The water distribution obtained in this manner is shown for slices collected at two different conditions: i) at $1 \mathrm{~V}, \sim 0 \mathrm{~A} / \mathrm{cm}^{2}$ and, ii) at $0.6 \mathrm{~V}$, where the cell is operating at high current density $\left(1 \mathrm{~A} / \mathrm{cm}^{2}, 0.6 \mathrm{~W} / \mathrm{cm}^{2}\right)$. Differences in the quantity and distribution of water are detected throughout the device (Fig. 1B, far right column) and local water accumulation is observed, especially inside the ionomer membrane under the landing areas where the flow field structure touches the MEA. While not rigidly ordered, X-ray scattering from the ionomer produces several features over a very wide angular range, including the well-known nanoscale ionic/hydrophobic phase segregation $\left(\sim 0.15 \AA^{-1}\right.$, Fig. S16), and semicrystalline packing of the backbone matrix $\left(\sim 2.5 \AA^{-1}\right.$, Fig. S5). Unfortunately, the water, ionomer and carbon content in 
pixels containing large quantities of Pt (i.e. inside the catalyst layer specifically) is difficult to obtain as the weak scattering from the light materials is masked by the high attenuation of Pt. These limitations can be addressed by imaging hydration gradients inside the cell with SAXS-CT, which is extremely sensitive to ionomer hydration. The phenomena of water collecting underneath the fuel cell flow fields has been studied for decades using X-rays ${ }^{37}$ and neutrons ${ }^{17,38}$. Quantitative measurements of ionomer nanostructure by SAXS add significant value to standard water imaging experiments, since hydration inside the polymer electrolyte can be precisely determined. ${ }^{39,40}$ SAXS-CT allows the spatial correlation of ionomer nanostructure, with the water content in the other cell constituents while using the same X-ray probe. A SAXS-CT slice collected in a separate experiment during cell operation $\left(0.8 \mathrm{~A} / \mathrm{cm}^{2}, \sim 0.59 \mathrm{~V}, 80 \%\right.$ relative humidity) reveals the heterogeneous hydration of the membrane throughout the MEA with significantly better detail than in the XRD measurement (Fig. 1C). The SAXS curves were modelled as a power law background with a Gaussian ionomer peak (Fig. S16). ${ }^{41}$ The thin membrane was not perfectly aligned with the plane of the slice, so we restrict our analysis to the regions where the ionomer peak is clearly visible. Comparatively wet and dry regions inside the membrane can be resolved through changes in the $d$-spacing of the ionomer peak which indicates the distance between ionic nanodomains increases from 3.5 to $3.8 \mathrm{~nm}$ in the preferentially hydrated regions. The wet and dry regions exhibit a vertically lined pattern correlated with the positions of the flow field. This pattern is similar to the water distribution from the XRD-CT measurements, validating the data obtained by less precise XRD pattern analysis (note that the cathode and anode flow field ribs were aligned parallel to one another for the SAXS imaging). The SAXS shows that the membrane is partially hydrated, about $10 \%$ by weight (fully hydrated membranes contain up to $25 \%$ water ${ }^{42,43}$ ). Streaks in the SAXS-CT image show the membrane underneath the flow field rib is preferentially hydrated 
pointing to the same hydration distribution pattern within the membrane as the liquid water in the carbon diffusion layers observed previously. ${ }^{38}$ SAXS-CT analysis confirms that the nanoscale spatial heterogeneities arising from significant hydration gradients are correlated to the flow field pattern. Heterogeneity in the XRD-CT images is therefore also likely connected to the inhomogeneous distribution of water inside different layers of the device.

\section{Degradation after a potentiostatic hold at $1 \mathrm{~V}$}

To correlate the water distribution inside the cell to the nanostructural heterogeneity of the catalyst and aging mechanisms within the MEA ${ }^{44,45}$, we extract the catalyst's structural parameters from the XRD-CT patterns. The intensity parameter of the Pt diffraction signals corresponds to the quantity of material, while the peak widths are related to the average particle size and defect content of the Pt catalyst. The main complication limiting such analysis on full scale operational devices are peak broadening artefacts known as parallax errors (i.e. peak broadening as a function of $\tan 2 \theta$, Figs. S9 \& 10). These distortions in XRD-CT images of large samples $>1 \mathrm{~cm}$ have until now limited the quality and reliability of nanostructural parameters obtained from the diffraction data (e.g. lattice parameter, peak widths) ${ }^{35}$ Here we disclose a new tomographic algorithm called Direct Least-Squares Reconstruction (DLSR) which provides a generalized solution to this problem, and corrects for parallax distortion in arbitrarily large samples. Therefore, the practical maximum sample size for XRD-CT is limited only by penetration of the X-ray beam. This advance extends the capabilities of scattering-contrast tomography from laboratory specimens to samples normally imaged using hospital-style CT scanners, including practical fuel cell devices. The DLSR algorithm quantitatively recovers the diffraction profile (Figs. S11-S15) and the microstructure of the Pt catalyst in the fuel cell, including the particle size and strain. The computationally expensive 
nature of the parallax-corrected reconstruction currently limits the image resolution, although rapid advances in software capability are expected. A detailed discussion on parallax artefacts, its correction using the DLSR algorithm, and benchmarking versus conventional algorithms can be found in the Supplementary Information.

Figure 2 shows images of the Pt nanostructure obtained from Rietveld analysis of a single XRDCT image slice collected through the cathode of a degraded MEA during operation at $1 \mathrm{~A} / \mathrm{cm}^{2}$. The degradation was induced by holding the potential at $1 \mathrm{~V}$ for 10 hours at $80^{\circ} \mathrm{C}$, which is slightly above open circuit voltage (ca. $0.95 \mathrm{~V}) .{ }^{15}$ These high, cell reversing potentials lead to Pt oxidation and degradation. ${ }^{46}$ Variations in the Pt intensity map (Fig. 2A), reflect the mechanical distortion of the catalyst coated membrane inside the pressurized cell during operation. The region where the ionomer membrane protrudes into the measured slice shows particles up to $100 \mathrm{~nm}$ in size (yellow arrow, in Fig. 2B). While degradation gradients through the cross-section of catalyst layers have been previously reported using ex situ $\mathrm{TEM}^{18,47}$, the size of the Pt nanoparticles in the region of these protrusions are an order of magnitude larger than expected. Nanoparticles of this size are typically found in the "Pt band", formed near and inside the membrane of aged MEAs. ${ }^{48,49}$ Even though the formation of this Pt band has been identified as a key factor in the stability of fieldtested MEAs ${ }^{50}$, in situ detection of Pt band formation has not been previously reported. Higher resolution imaging and aging conditions which emphasize Pt band formation will be necessary to confirm the localization of these large Pt particles inside the membrane. 

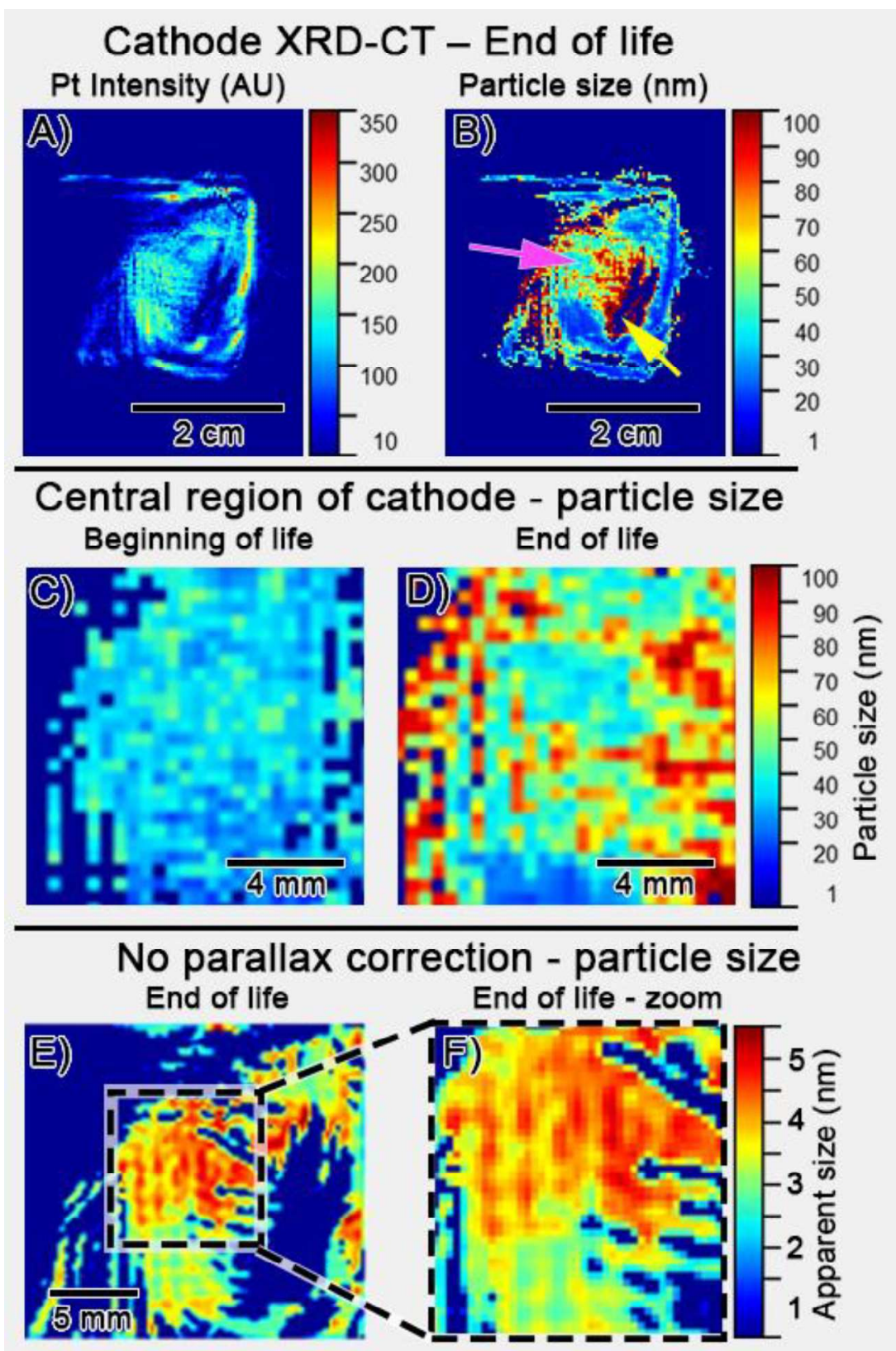

Figure 2. XRD-CT of Pt cathode catalyst. A) Pt intensity distribution over the single CT slice.

B) Pt particle size map, parallax corrected. The yellow arrow indicates the region where the ionomer membrane protrudes into the slice. C, D) Particle size maps for identical regions in the central region of the electrode (magenta arrow in B) at the beginning and end of testing, respectively. E) High resolution crystallite size map for central region of the electrode at end of testing, without parallax correction. F) Magnification of E) showing detailed particle size map. 
The central region of the sample (Fig. 2B, magenta arrow) can be seen in greater detail in Figs. $2 C \& \mathrm{D}$. Although the spatial resolution of these parallax corrected images is limited $(500 \mu \mathrm{m})$ the particle size in the sample at the beginning of testing (Fig. 2C) is much more spatially homogeneous than after testing (Fig. 2D). Higher spatial resolution XRD-CT images can be obtained if parallax correction is neglected (Figs. $2 \mathrm{E}$ and $2 \mathrm{~F}, 200 \mu \mathrm{m}$ resolution), with the tradeoff that the calculated particle sizes are qualitative and only comparative analysis is possible. Vertical and horizontal streaks are visible in the uncorrected maps, where the particles are systematically larger in regions covered by the flow field plates. Therefore, the morphological degradation of catalyst nanoparticles in these regions is more severe, coincident with previously observed thinning of the membrane and local Pt corrosion. ${ }^{51,52}$ The specific factors responsible for this nanoscale heterogeneity at high potentials are not easily decoupled. However, the link between flow field design and water content detected by SAXS-CT, and the correlation to the water distribution in the cell with catalyst degradation suggests that locally altered concentration and mass transport of dissolved species $\left(\mathrm{O}_{2}, \mathrm{H}^{+}, \mathrm{Pt}^{2 / 4+}\right)$ underneath the flow field ribs enhances degradation. A detailed understanding of how these complex gradients produce heterogeneous aging requires further study under well-defined aging conditions, likely guided by input from the growing fuel cell modelling community.

\section{Degradation during accelerated stress testing in PEMFC vs conventional cells}

Given the heterogeneity observed inside the catalyst layer during aging in an operating PEMFC device, the relevance of aging data from laboratory model systems deserves scrutiny because catalyst durability is principally assessed using cyclic voltammetry in ultrahigh purity liquid electrolyte at room temperature on a rotating disc electrode (RDE).$^{53,54}$ To evaluate the differences in these environments, the most popular catalyst AST protocol (sweeping between 0.6-1.0 V at 50 
$\mathrm{mV} / \mathrm{s}$ with $\mathrm{Ar}$ atmosphere on the cathode) was employed on the same commercial catalyst (Fig. S21) inside the PEMFC and with a conventional three electrode RDE cell. ${ }^{2} \mathrm{X}$-ray diffraction was measured in situ at multiple locations in the cathode throughout the AST of the PEMFC sample and transmission electron microscopy (TEM) images were collected for both the PEMFC and the RDE cell catalyst at the beginning and end of the test.

Both catalyst particle ripening and dissolution of Pt in the PEMFC sample are directly observed during the AST. The mean crystallite size of the Pt increases from $4.6 \mathrm{~nm}$ to $10.3 \mathrm{~nm}$ (Fig. 3, top) and approximately $30 \%$ of the Pt in the cathode dissolved (Fig. 3, bottom), which is consistent with previous work. ${ }^{14,46}$ Neither parameter follows a linear trend with the number of cycles: a large fraction of the overall change takes place in the first few cycles and the degradation slowly diminishes in effect without reaching a plateau. ${ }^{44}$ 


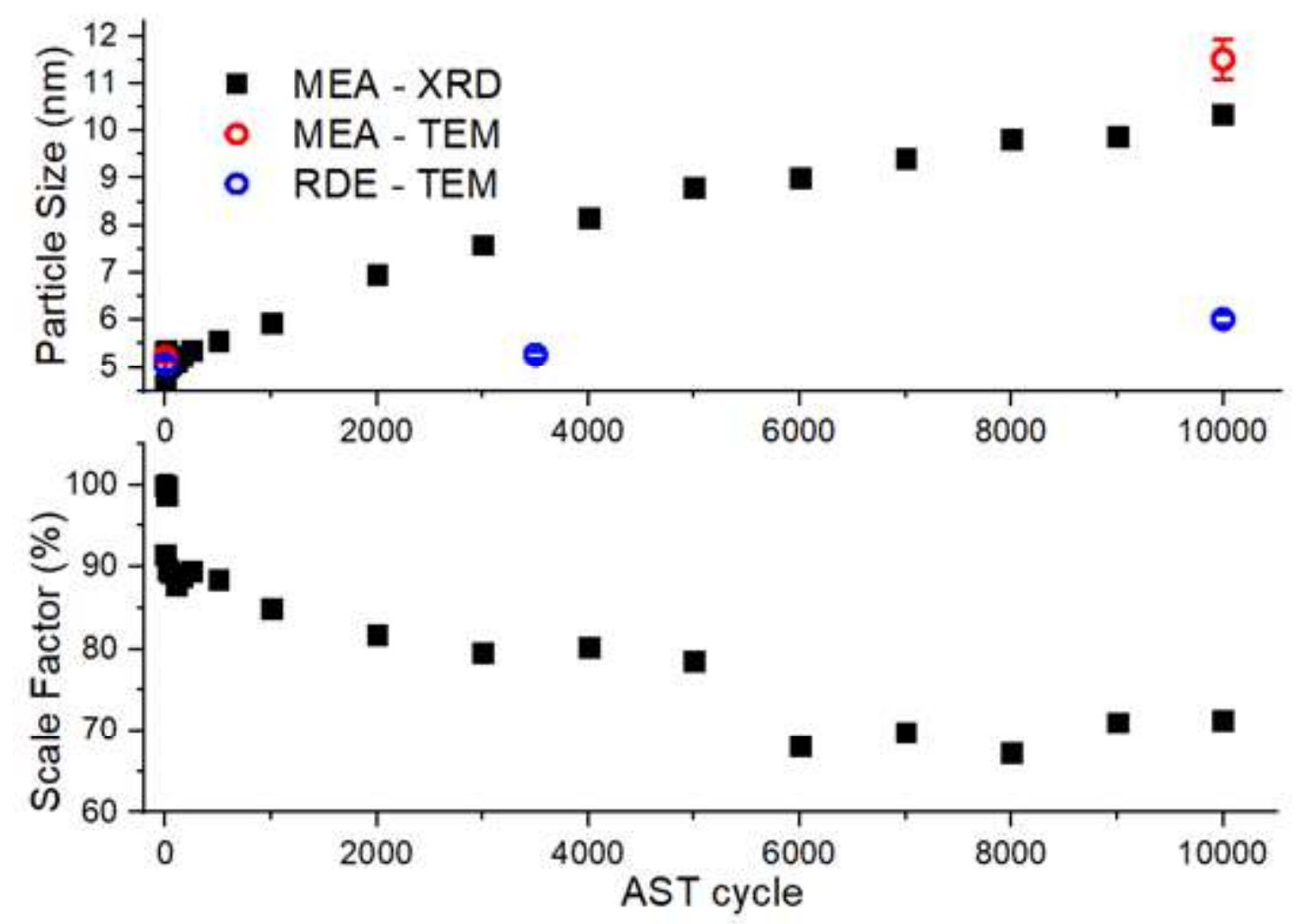

Figure 3. Particle size (top) and percentage of Pt remaining in electrode (bottom) over $10^{4}$ cycles of accelerated stress testing $(0.6-1.0 \mathrm{~V}, 50 \mathrm{mV} / \mathrm{s})$ determined from Rietveld analysis. Mean particle sizes for the full MEA cathode and rotating disc electrode (RDE) determined by electron microscopy are overlaid (red and blue circles, respectively). The temperature of the PEM and RDE cells during ageing was $80^{\circ} \mathrm{C}$ and $20^{\circ} \mathrm{C}$, respectively. The error estimated from the Rietveld covariance matrix is smaller than the plotted XRD markers. The TEM data error bars correspond to the standard error of the log-normal fit.

As anticipated, the catalyst in the PEMFC aged dramatically faster than inside a conventional RDE cell. These differences can be attributed to the PEMFC environment, including higher temperature, lower $\mathrm{pH}$, and enhanced mass transport of dissolved species, all of which promote corrosion of metallic catalysts. Although no tomography was performed, XRF mapping of the 
MEA sample after ageing showed that the dissolution was fairly homogeneous and XRD at multiple locations, both in the channels and landing areas, yielded similar results (Fig. S26). These data indicate that the chemical environment created inside the fuel cell during this AST profile is more homogeneous than the cell degraded by potentiostatic hold at $1 \mathrm{~V}$, and questions the utility of current ASTs to assess catalyst stability during PEMFC operation. This is because the chemical and temperature gradients, which define the degradation dynamics as discussed above, are linked to faradaic reactions, and are suppressed during stress testing under inert atmosphere. Therefore, the only reliable way to benchmark the catalyst stability, is to study the materials in a PEMFC device during operation. Furthermore, the predictions obtained from laboratory model systems are substantially and systematically different than catalyst degradation in devices.

\section{Distinguishing catalyst degradation mechanisms through XRD}

Studies which track the dissolution of Pt inside operating PEMFCs are relatively rare. In this case, the quantity of Pt observed in situ by XRD can be correlated to the electrochemical surface area (ECSA) of the catalyst measured throughout the test. The ratio of the ECSA to Pt loading throughout the AST is related to the surface-area-to-volume ratio of the catalyst, which can be used to probe degradation mechanisms, since different mechanisms produce characteristic trends. Processes such as local electrochemical disconnection, surface activation, or partial corrosion or larger particles produce increasing ECSA / loading ratios. Aggregation and ripening degradation modes produce decreasing ratios, while catalyst detachment from the support followed by dissolution would maintain a constant ratio. The observed trend is the sum of all simultaneous degradation modes. The shape of the normalized ECSA / Pt loading curve for the MEA is presented in Figure 4A. The ECSA is initially unstable and reaches a maximum after the first 100 cycles (attributed to surface cleaning), even though 12\% of the Pt loading dissolves during this activation 
phase. The ECSA / Pt loading ratio then decreases smoothly between cycle 100 and 10000. During this second phase, only $16 \%$ of the catalyst dissolves/detaches, but $63 \%$ of the ECSA is lost to ripening, aggregation, and other mechanisms altering the morphology, but not the quantity of Pt. The large difference between these numbers highlights both the importance of Pt redeposition and particle-particle interactions in the degradation mechanism of commercial PEMFC catalysts, and how Pt corrosion represents just one (but critical) step. We predict that the aging of shapecontrolled catalysts under well-defined conditions would benefit even further from direct measurements of surface area to volume ratios during operando experiments. 

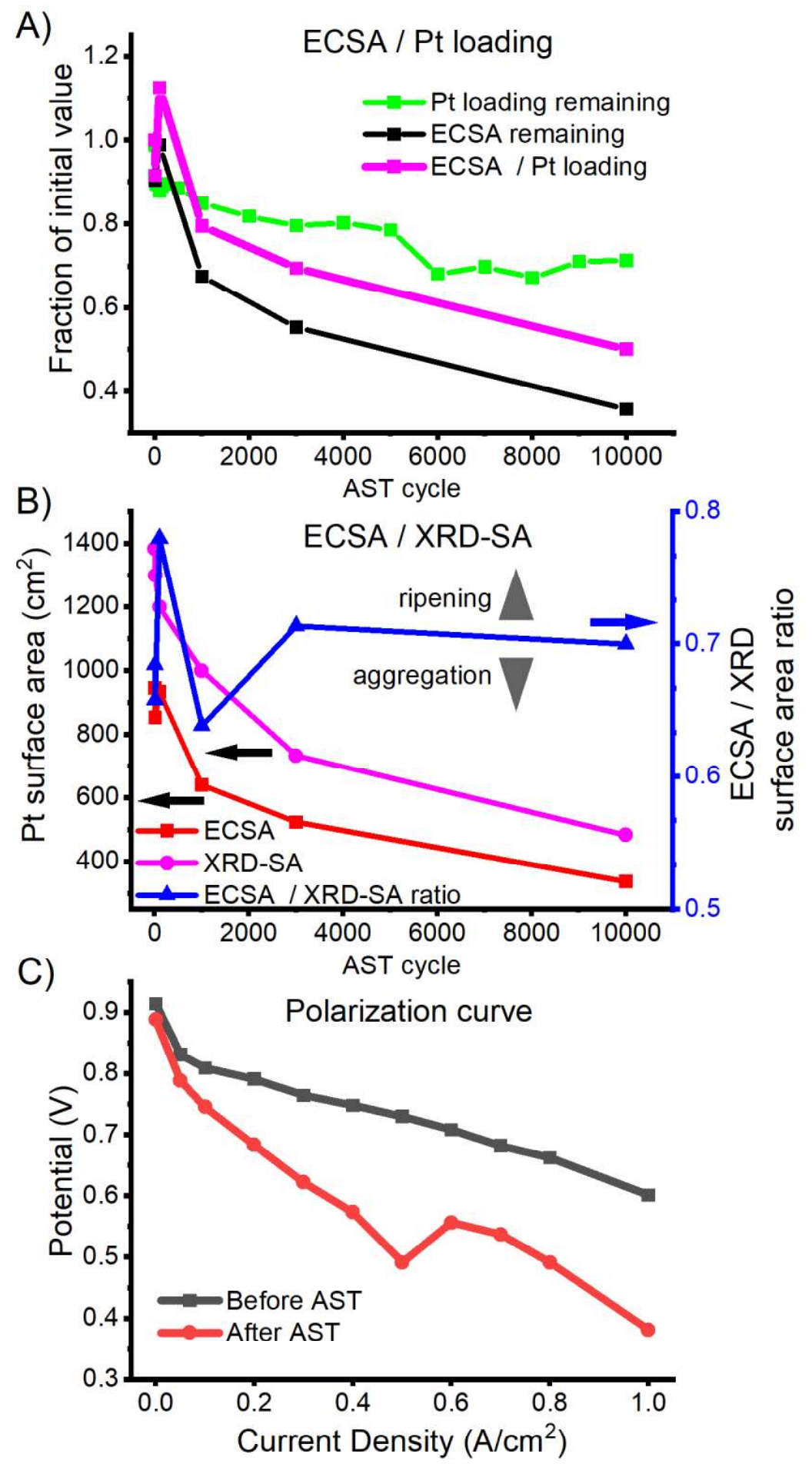

Figure 4. A) Ratio of metallic Pt to ECSA remaining as a function of AST cycle number. Both values have been normalized to the first cycle. B) Pt ECSA and total theoretical surface area calculated from the XRD loading and crystallite size (XRD-SA), and their ratio over the course of 
the AST cycling. The Pt catalyst was modelled as monodisperse spheres, using the parameters from Figure 3. C) Polarization curves of MEA before and after AST cycling, extracted from Fig. S28. The cell was operated at $80^{\circ} \mathrm{C}$, flowing $\mathrm{H}_{2} /$ air at $100 \% \mathrm{RH}$.

The ratio of the ECSA to crystallite size by XRD allows ripening and aggregation degradation mechanisms to be decoupled. The observed crystallite size is unaffected by aggregation, but responds to ripening/coalescence processes, while the ECSA is sensitive towards both. The loading and crystallite size measured with XRD allow the "total" Pt surface area of the catalyst to be calculated on an absolute scale. The electrochemically connected fraction, dispersion, or "utilization" of the Pt catalyst can be estimated from the ratio of the ECSA and this XRD calculated surface area (XRD-SA). Aggregation would cause the observed ECSA / XRD-SA ratio to decrease, while coalescence and ripening produce either higher or constant values depending on the catalyst morphology. The total surface area of the catalyst measured by cyclic voltammetry and calculated by XRD in $\mathrm{cm}^{2}$, along with the ECSA / XRD-SA ratio of the two are shown in Figure 4B. The catalyst was approximated as monodisperse spheres, with no corrections for surface area blocked by carbon support, electrochemically disconnected particles or aggregation. Following the initial 100 cycles over which the catalyst surface is cleaned and the ECSA increases, the ECSA/XRD-SA ratio decreases to $64 \%$ at 1000 cycles, then increases and stabilizes at $70-71 \%$ for the remainder of the AST. We attribute these changes to an aggregation phase, followed by coalescence and ripening. The total range of the ECSA/XRD-SA ratio is relatively stable (64$78 \%$ ), even though the total surface area changes drastically over the course of the AST. This indicates that aggregation processes only account for a few percent of the changes in ECSA, while coalescence and ripening phenomena are responsible for the majority of the decrease in surface 
area. The $\sim 70 \%$ accessibility of the total Pt surface calculated from XRD is physically reasonable considering both the simplicity of this model, and that the carbon support and Pt aggregates block the remaining $\sim 30 \%$ of a Pt crystallite's surface. The drastic loss of cathode ECSA during the AST produces clear performance degradation of the PEMFC device, as shown in the ORR polarization curves collected before and after the AST (Fig. 4C). The deep structural insight provided by operando XRD greatly enhances the value of even simple AST experiments on standard commercial catalysts. Ratios of microstructural parameters allow the contributions of competing degradation mechanisms to be decoupled.

Major advances in XRD-CT reconstruction algorithms allow for simultaneous assessment of nanostructural and chemical heterogeneities inside an operational $5 \mathrm{~cm}^{2}$. Interactions between different phases can be correlated at high current densities with a single probe. The XRD-CT images provide nanoscale information and show spatially resolved differences in the aging of catalyst particles, which correlate to the flow field geometry and water distribution within the device observed by SAXS-CT. Therefore, the macroscopic design of the cell has a decisive role in the nanoscopic degradation phenomena of the catalyst, which needs to be taken into account at all levels of PEMFC design. Accelerated stress testing tracked by in situ X-ray diffraction indicates that catalyst aging inside PEMFCs is extremely aggressive when compared to conventional RDE testing, even in the absence of faradaic currents which further accelerate the ageing. X-ray scattering tomography and operando AST measurements are shown to be a powerful platform for deconvoluting the degradation mechanisms of electrocatalysts. Stress tests performed in a liquid cell should be critically evaluated in order to predict catalyst degradation rates and mechanisms in functional systems. The presented strategy for deep, in situ and operando characterization bridging fundamental chemistry and device engineering is generally applicable to the next generation of 
batteries, solar cells, and other energy conversion and storage systems with few compromises in electrochemical performance. These devices are composed of complex materials, where chemical reactivity, transport phenomena, and degradation mechanisms are intrinsically coupled, yielding heterogeneous distributions of phases. Advanced tools capable of providing real-time, multi-scale chemical and structural information are therefore invaluable towards understanding the evolution of these systems. We anticipate that such non-intrusive and holistic approaches, which combine several X-ray scattering tomography techniques, will enhance understanding of the roles, and interactions between different constituents, allowing next-generation materials to be incorporated into PEMFCs and other electrochemical devices.

\section{Supporting Information}

Detailed descriptions of the sample preparation, small angle X-ray scattering, X-ray diffraction, computed tomography data analysis algorithms, 3D reconstructions, Rietveld refinement, electron microscopy, particle size analysis, X-ray spectroscopic imaging, and electrochemical characterization can be found in the Supporting Information.

\section{Notes}

I.M., A.V., R.C., J.P., M.V.B., E.A.F., T.A., T.S., D.B., D.P.W, and J.D. performed the XRD experiments. N.M, S.E., F.M., S.L., A.M, and J.D. performed the SAXS experiments. A.V., A.C., and S.J. devised and implemented the DLSR algorithm. I.M. and J.D. wrote the manuscript. D.B., D.P.W., S.L., A.M., V.H., S.J., F.M., L.D. and J.D. supervised the work. All authors reviewed the manuscript.

The authors declare no competing financial interest.

\section{ACKNOWLEDGMENT}


This work was supported by Automotive Partnership Canada and NSERC. A.V. is supported through the European Union Horizon 2020 program under Grant Agreement No. 679933 (MEMERE). The SAXS-CT was funded by Institut Carnot Energies du Futur under the STATUQUEAU project.

\section{REFERENCES}

(1) Staffell, I.; Scamman, D.; Velazquez Abad, A.; Balcombe, P.; Dodds, P. E.; Ekins, P.; Shah, N.; Ward, K. R. Energy Environ. Sci. 2019, 12 (2), 463-491.

(2) Office of Energy Efficiency and Renewable Energy. 2019 Annual Merit Review and Peer Evaluation Report; 2019.

(3) Chen, X.; Kang, Y.; Huo, Z.; Zhu, Z.; Huang, W.; Xin, H. L.; Snyder, J. D.; Li, D.; Herron, J. A.; Mavrikakis, M.; Chi, M.; More, K. L.; Li, Y.; Markovic, N. M.; Somorjai, G. A.; Yang, P.; Stamenkovic, V. R.; Chen, C.; Kang, Y.; Huo, Z.; Zhu, Z.; Huang, W.; Xin, H. L.; Snyder, J. D.; Li, D.; Herron, J. A.; Mavrikakis, M.; Chi, M.; More, K. L.; Li, Y.; Markovic, N. M.; Somorjai, G. A.; Yang, P.; Stamenkovic, V. R. Science 2014, 343 (6177), 1339-1343.

(4) Stephens, I. E. L.; Bondarenko, A. S.; Grønbjerg, U.; Rossmeisl, J.; Chorkendorff, I. Energy Environ. Sci. 2012,5 (5), 6744.

(5) Kocha, S. S.; Shinozaki, K.; Zack, J. W.; Myers, D. J.; Kariuki, N. N.; Nowicki, T.; Stamenkovic, V.; Kang, Y.; Li, D.; Papageorgopoulos, D. Electrocatalysis 2017, 8 (4), 366-374.

(6) Kongkanand, A.; Mathias, M. F. J. Phys. Chem. Lett. 2016, 7 (7), 1127-1137.

(7) Ly, A.; Asset, T.; Atanassov, P. J. Power Sources 2020, 478, 228516.

(8) Banham, D.; Ye, S. ACS Energy Lett. 2017, 2 (3), 629-638.

(9) Kodama, K.; Nagai, T.; Kuwaki, A.; Jinnouchi, R.; Morimoto, Y. Nat. Nanotechnol. 2021, 16 (2), 140-147.

(10) Gocyla, M.; Kuehl, S.; Shviro, M.; Heyen, H.; Selve, S.; Dunin-Borkowski, R. E.; Heggen, M.; Strasser, P. ACS Nano 2018, $12(6), 5306-5311$.

(11) Pizzutilo, E.; Geiger, S.; Grote, J.-P.; Mingers, A.; Mayrhofer, K. J. J.; Arenz, M.; Cherevko, S. J. Electrochem. Soc. 2016, 163 
(14), F1510-F1514.

(12) Shao, M.; Chang, Q.; Dodelet, J.-P.; Chenitz, R. Chem. Rev. 2016, 116 (6), 3594-3657.

(13) Alsabet, M.; Grden, M.; Jerkiewicz, G. J. Electroanal. Chem. 2006, 589 (1), 120-127.

(14) Gilbert, J. A.; Kariuki, N. N.; Subbaraman, R.; Kropf, A. J.; Smith, M. C.; Holby, E. F.; Morgan, D.; Myers, D. J. J. Am. Chem. Soc. 2012, 134 (36), 14823-14833.

(15) Guilminot, E.; Corcella, A.; Charlot, F.; Maillard, F.; Chatenet, M. J. Electrochem. Soc. 2007, 154 (1), B96.

(16) Ahmed, M.; Morgan, D.; Attard, G. A.; Wright, E.; Thompsett, D.; Sharman, J. J. Phys. Chem. C 2011, 115 (34), $17020-$ 17027.

(17) Fairweather, J. D.; Spernjak, D.; Weber, A. Z.; Harvey, D.; Wessel, S.; Hussey, D. S.; Jacobson, D. L.; Artyushkova, K.; Mukundan, R.; Borup, R. L. J. Electrochem. Soc. 2013, 160 (9), F980-F993.

(18) Dubau, L.; Castanheira, L.; Maillard, F.; Chatenet, M.; Lottin, O.; Maranzana, G.; Dillet, J.; Lamibrac, A.; Perrin, J.-C.; Moukheiber, E.; ElKaddouri, A.; De Moor, G.; Bas, C.; Flandin, L.; Caqué, N. Wiley Interdiscip. Rev. Energy Environ. 2014, $3(6), 540-560$.

(19) Meyer, Q.; Zeng, Y.; Zhao, C. Adv. Mater. 2019, 31 (40), 1-25.

(20) Cheng, L.; Khedekar, K.; Rezaei Talarposhti, M.; Perego, A.; Metzger, M.; Kuppan, S.; Stewart, S.; Atanassov, P.; Tamura, N.; Craig, N.; Zenyuk, I. V.; Johnston, C. M. Adv. Energy Mater. 2020, 10 (28), 2000623.

(21) Takao, S.; Sekizawa, O.; Samjeské, G.; Nagamatsu, S.; Kaneko, T.; Yamamoto, T.; Higashi, K.; Nagasawa, K.; Uruga, T.; Iwasawa, Y. J. Phys. Chem. Lett. 2015, 6 (11), 2121-2126.

(22) Shao, Y.; Yin, G.; Gao, Y. J. Power Sources 2007, 171 (2), 558-566.

(23) Lopez-Haro, M.; Guétaz, L.; Printemps, T.; Morin, A.; Escribano, S.; Jouneau, P.-H.; Bayle-Guillemaud, P.; Chandezon, F.; Gebel, G. Nat. Commun. 2014, 5 (1), 5229.

(24) Mukundan, R.; Borup, R. L. Fuel Cells 2009, 9 (5), 499-505.

(25) Wu, J.; Zhu, X.; West, M. M.; Tyliszczak, T.; Shiu, H. W.; Shapiro, D.; Berejnov, V.; Susac, D.; Stumper, J.; Hitchcock, A. P. 
J. Phys. Chem. C 2018, 122 (22), 11709-11719.

(26) Zenyuk, I. V.; Parkinson, D. Y.; Hwang, G.; Weber, A. Z. Electrochem. commun. 2015, 53, 24-28.

(27) Xu, H.; Marone, F.; Nagashima, S.; Nguyen, H.; Kishita, K.; Büchi, F. N.; Eller, J. ECS Trans. 2019, 92 (8), 11-21.

(28) Tuaev, X.; Rudi, S.; Petkov, V.; Hoell, A.; Strasser, P. ACS Nano 2013, 7 (7), 5666-5674.

(29) Kleuker, U.; Suortti, P.; Weyrich, W.; Spanne, P. Phys. Med. Biol. 1998, 43 (10), 2911-2923.

(30) Schroer, C. G.; Kuhlmann, M.; Roth, S. V.; Gehrke, R.; Stribeck, N.; Almendarez-Camarillo, A.; Lengeler, B. Appl. Phys. Lett. 2006, 88 (16), 164102.

(31) Jacques, S. D. M.; Di Michiel, M.; Beale, A. M.; Sochi, T.; O’Brien, M. G.; Espinosa-Alonso, L.; Weckhuysen, B. M.; Barnes, P. Angew. Chemie Int. Ed. 2011, 50 (43), 10148-10152.

(32) Li, T.; Heenan, T. M. M. M.; Rabuni, M. F.; Wang, B.; Farandos, N. M.; Kelsall, G. H.; Matras, D.; Tan, C.; Lu, X.; Jacques, S. D. M. M.; Brett, D. J. L. L.; Shearing, P. R.; Di Michiel, M.; Beale, A. M.; Vamvakeros, A.; Li, K. Nat. Commun. 2019, 10 (1), 1497.

(33) Vamvakeros, A.; Jacques, S. D. M.; Di Michiel, M.; Matras, D.; Middelkoop, V.; Ismagilov, I. Z.; Matus, E. V.; Kuznetsov, V. V.; Drnec, J.; Senecal, P.; Beale, A. M. Nat. Commun. 2018, 9 (1), 4751.

(34) Finegan, D. P.; Vamvakeros, A.; Cao, L.; Tan, C.; Heenan, T. M. M.; Daemi, S. R.; Jacques, S. D. M.; Beale, A. M.; Di Michiel, M.; Smith, K.; Brett, D. J. L.; Shearing, P. R.; Ban, C. Nano Lett. 2019, 19 (6), 3811-3820.

(35) Martens, I.; Vamvakeros, A.; Chattot, R.; Blanco, M. V.; Rasola, M.; Pusa, J.; Jacques, S. D. M.; Bizzotto, D.; Wilkinson, D. P.; Ruffmann, B.; Heidemann, S.; Honkimäki, V.; Drnec, J. J. Power Sources 2019, 437, 226906.

(36) Holdcroft, S. Chem. Mater. 2014, 26 (1), 381-393.

(37) Oberholzer, P.; Boillat, P. J. Electrochem. Soc. 2014, 161 (1), F139-F152.

(38) Kulkarni, N.; Cho, J. I. S.; Rasha, L.; Owen, R. E.; Wu, Y.; Ziesche, R.; Hack, J.; Neville, T.; Whiteley, M.; Kardjilov, N.; Markötter, H.; Manke, I.; Shearing, P. R.; Brett, D. J. L. J. Power Sources 2019, 439, 227074.

(39) Kusoglu, A.; Weber, A. Z. Chem. Rev. 2017, 117 (3), 987-1104. 
(40) Hussey, D. S.; Spernjak, D.; Weber, A. Z.; Mukundan, R.; Fairweather, J.; Brosha, E. L.; Davey, J.; Spendelow, J. S.; Jacobson, D. L.; Borup, R. L. J. Appl. Phys. 2012, 112 (10), 104906.

(41) Martinez, N.; Gebel, G.; Blanc, N.; Boudet, N.; Micha, J.-S. S.; Lyonnard, S.; Morin, A. ACS Appl. Energy Mater. 2019, 2 (5), 3071-3080.

(42) Shi, S.; Weber, A. Z.; Kusoglu, A. J. Memb. Sci. 2016, 516, 123-134.

(43) Ge, N.; Banerjee, R.; Muirhead, D.; Lee, J.; Liu, H.; Shrestha, P.; Wong, A. K. C.; Jankovic, J.; Tam, M.; Susac, D.; Stumper, J.; Bazylak, A. J. Power Sources 2019, 422, 163-174.

(44) Asset, T.; Gommes, C. J.; Drnec, J.; Bordet, P.; Chattot, R. R.; Martens, I.; Nelayah, J.; Job, N.; Maillard, F.; Dubau, L. ACS Catal. 2019, 9 (1), 160-167.

(45) Chattot, R.; Martens, I.; Scohy, M.; Herranz, J.; Drnec, J.; Maillard, F.; Dubau, L. ACS Energy Lett. 2020, 5 (1), $162-169$.

(46) Cherevko, S.; Kulyk, N.; Mayrhofer, K. J. J. Nano Energy 2016, 29, 275-298.

(47) Chen, S.; Gasteiger, H. A.; Hayakawa, K.; Tada, T.; Shao-Horn, Y. J. Electrochem. Soc. 2010, 157 (1), A82.

(48) Ferreira, P. J.; la O', G. J.; Shao-Horn, Y.; Morgan, D.; Makharia, R.; Kocha, S.; Gasteiger, H. A. J. Electrochem. Soc. 2005, $152(11)$, A2256.

(49) Yasuda, K.; Taniguchi, A.; Akita, T.; loroi, T.; Siroma, Z. J. Electrochem. Soc. 2006, 153 (8), A1599.

(50) Macauley, N.; Alavijeh, A. S.; Watson, M.; Kolodziej, J.; Lauritzen, M.; Knights, S.; Wang, G.; Kjeang, E. J. Electrochem. Soc. 2014, 162 (1), F98-F107.

(51) Durst, J.; Lamibrac, A.; Charlot, F.; Dillet, J.; Castanheira, L. F.; Maranzana, G.; Dubau, L.; Maillard, F.; Chatenet, M.; Lottin, O. Appl. Catal. B Environ. 2013, 138-139, 416-426.

(52) White, R. T.; Wu, A.; Najm, M.; Orfino, F. P.; Dutta, M.; Kjeang, E. J. Power Sources 2017, 350, 94-102.

(53) Nandjou, F.; Poirot-Crouvezier, J.-P.; Chandesris, M.; Blachot, J.-F.; Bonnaud, C.; Bultel, Y. J. Power Sources 2016, 326, 182-192.

(54) Mittermeier, T.; Weiß, A.; Hasché, F.; Gasteiger, H. A. J. Electrochem. Soc. 2018, 165 (16), F1349-F1357. 
